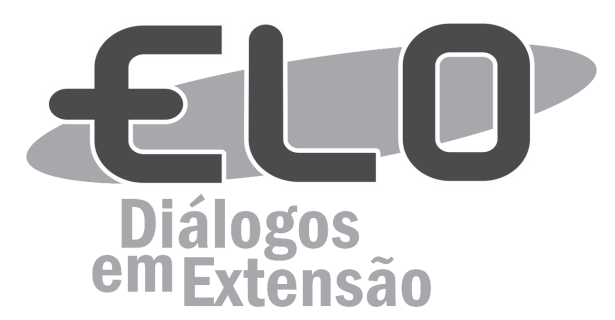

\title{
Divulgando a neurociência: ações para desmistificação de neuromitos
}

João Pedro Sperluk Arce ${ }^{1}$, Mayara Marques de Souza ${ }^{2}$, Liane da Silva de Vargas ${ }^{3}$, Pâmela Billig Mello-Carpes ${ }^{4}$

\begin{abstract}
Resumo: No ambiente escolar acredita-se que a prática pedagógica baseada em informações equivocadas sobre o funcionamento do cérebro e sistema nervoso, nesse caso, os neuromitos, é uma das responsáveis pela lacuna existente entre a neurociência e educação. Sendo assim, o programa "POPNEURO: ações para a popularização e divulgação da neurociência" se propôs a trabalhar alguns neuromitos no espaço escolar, elucidando-os. Participaram das ações 113 alunos, sendo 51,3\% meninas e 48,6\% meninos, com idade média de 11 anos. As ações contaram com atividades teóricas e práticas e cada ação teve duração de 1 h e 30min. Como forma de avaliação, foram aplicados questionários estruturados pré e pós-intervenção, este último logo após a ação (imediato) e 30 dias após a ação (tardio). Verificamos que as ações foram exitosas, uma vez que houve aumento no conhecimento dos alunos após as intervenções, elucidando os conceitos trabalhados de forma simples, lúdica e, principalmente, prática, relacionando-os com o cotidiano escolar.
\end{abstract}

Palavras-chave: Cérebro. Educação. Divulgação científica. Popularização da ciência.

Área Temática: Educação.

\section{Disseminating neuroscience: actions to demystify neuromytes}

Abstract: In the school environment, it is believed that the pedagogical practice based on misinformation about the functioning of the brain and the nervous system, in this case, the neuromyts, is one of the reasons for the gap that exists between neuroscience and education. Thus, the program "POPNEURO: actions to promote the popularization and dissemination of neuroscience" has proposed to work some neuromyts in the school, elucidating them. 113 students participated in the actions, of which $51.3 \%$ were girls and $48.6 \%$ were boys, with a mean age of 11 years. The actions counted on theoretical and practical activities and each action lasted 1h and 30min. As a form of evaluation, pre and post-intervention structured questionnaires were applied, the latter immediately after the action (immediate) and 30 days after the action (late). We verified that the actions were successful, since there was an increase in the knowledge of the students after the interventions, elucidating the concepts worked in a simple, playful and, mainly, practical form, related them to the school routine.

Keywords: Brain. Education. Scientific divulgation. Science popularization.

\section{Promocionando la neurociencia: acciones destinadas a desacreditar los neuromitos}

Resumen: En el ambiente escolar se cree que la práctica pedagógica basada en información engañosa sobre el funcionamiento del cerebro y del sistema nervioso, en este caso, los neuromitos, es una de las razones de la brecha existente entre la neurociencia y la educación. Por lo tanto, el programa

\footnotetext{
${ }^{1}$ Discente do curso de Enfermagem, bolsista do programa POPNEURO, Universidade Federal do Pampa, Campus Uruguaiana/RS.

${ }^{2}$ Discente do curso de Enfermagem, bolsista do programa POPNEURO, Universidade Federal do Pampa, Campus Uruguaiana/ RS.

${ }^{3}$ Doutoranda do PPG Fisiologia, colaboradora do programa POPNEURO, Universidade Federal do Rio Grande do Sul, Porto Alegre/RS.

${ }^{4}$ Professora adjunta da Universidade Federal do Pampa, Campus Uruguaiana/RS. BR 472 km 592 - Caixa postal 118 - CEP 97500-970//Fax: +55(55)39110211/

34218441.pamelacarpes@unipampa.edu.br
} 
"POPNEURO: acciones para popularización y difusión de la neurociencia" se propuso a trabajar algunos neuromitos en la escuela, buscando la aclaración de ellos. Participaron de las acciones 113 estudiantes, siendo 51,3\% mujeres y 48,6\% hombres, con edad media de 11 años. Las acciones contaran con actividades teóricas y prácticas y cada acción duró 1 hora y 30 minutos. Como una forma de evaluación, se aplicaron cuestionarios estructurados pre y post-intervención, este último poco después de la acción (inmediato) y 30 días después de la acción (tardio). Verificamos que las acciones tuvieron éxito, ya que hubo un aumento en el conocimiento de los estudiantes después de las intervenciones, elucidando los conceptos trabajados de una manera simple, lúdica y, sobre todo, práctica, relacionandolos con el cotidiano escolar.

Palabras clave: Cerebro. Educación. Divulgación científica. Popularización de la ciencia.

\section{Introdução}

Um neuromito pode ser caracterizado como uma informação equivocada a respeito de conceitos relacionados com o Sistema Nervoso (SN) que é disseminada em meio à população em geral (BUENO et al, 2015). Os neuromitos podem surgir de várias formas, como, por exemplo, a partir da interpretação errônea de uma leitura ou da má interpretação de dados científicos, ou, ainda, pela divulgação de informações infundadas pela mídia (DEKKER et al, 2012). O que geralmente acontece é que a população em geral, que não tem acesso ou não tem um conhecimento prévio acerca do funcionamento do SN, acaba acreditando e replicando essas falsas informações (BUENO et al, 2015). A afirmação de que existem períodos críticos para a aprendizagem, assim como a de que não existe neurogênese, e as relacionadas aos diferentes estilos de aprendizagem e à dominância dos hemisférios são exemplos dos neuromitos mais presentes entre as pessoas leigas (OECD, 2007).

O projeto "Cérebro e Aprendizagem" da Organization for Economic Cooperation and Development (OECD, 2002) classificou esses dados infundados ou mal entendidos como "neuromitos" e alertou para a rapidez e proporção em que estes se alastram e se perpetuam na sociedade e nas escolas. Alguns fatores que têm colaborado para isso são o avanço das pesquisas em neurociência, com muitas descobertas sobre o funcionamento do cérebro, e também o fácil acesso a informações e compartilhamento das mesmas por meio da internet. De acordo com Brockington e Mesquita (2016) um dos maiores problemas da rápida disseminação de mitos é a linguagem utilizada na tentativa de abranger um público fora da comunidade acadêmica, que é, em grande maioria, composta por pessoas leigas; sem a complexidade de uma leitura de um artigo científico, a simplificação do conteúdo acaba gerando equívocos e leituras pobres no que se trata de informações científicas.

No ambiente escolar acredita-se que a prática pedagógica baseada por informações equivocadas sobre o cérebro, nesse caso, os neuromitos, é uma das responsáveis pela lacuna existente entre a neurociência e a educação (DEKKER et al, 2012). Os professores que tem a sua prática educacional baseada em neuromitos acabam por contribuir na disseminação dessas informações equivocadas, as quais se propagam não só entre os alunos e seus familiares, mas também entre os próprios professores, formando um ciclo vicioso. Segundo Rato et al. (2013), o maior obstáculo para que a neurociência e a educação andem juntas, é a existência dos neuromitos.

Diante do exposto, torna-se necessário que os neuromitos sejam trabalhados em salas de aula, para que os equívocos e distorções em relação ao entendimento de como o cérebro funciona diminuam ou até mesmo sejam extintos. Percebendo essa necessidade, identificando o alto número de neuromitos difundido entre professores e alunos, e sabendo que a neurociência está a passos lentos para uma parceria sólida com a educação, foi criado um grupo de estudos, com encontros semanais, para discutir assuntos relacionados à neurociência e educação. Essas discussões posteriormente embasaram a preparação de ações de pesquisa e extensão para divulgar a neurociência, elucidando neuromitos, junto a professores e estudantes da rede pública de educação.

\section{Objetivos}

Sendo assim, os objetivos deste trabalho incluem relatar a metodologia organizacional utilizada para discutir temas atuais relacionados com a neurociência e educação, desmistificando alguns neuromitos, bem como avaliar o impacto das ações realizadas. 


\section{Metodologia}

Por meio da criação do programa de extensão "POPNEURO: Ações para a divulgação e popularização da neurociência junto à rede escolar do município de Uruguaiana/RS", firmou-se uma parceria entre a Universidade Federal do Pampa - UNIPAMPA, Campus Uruguaiana e a comunidade escolar da cidade, a qual possibilitou a realização de diversas atividades, aproximando conceitos de neurociência e a escola. A equipe executora do programa POPNEURO, bem como das atividades aqui relatadas é composta por três docentes pesquisadores, um da área de Neurociência (Ciências Biológicas), um da área de Saúde e um da área de Educação, além de dois alunos de pós-graduação na área de Ciências Biológicas e 23 estudantes de graduação, sendo eles do curso de licenciatura em Educação Física e dos cursos de bacharelado em Enfermagem, Farmácia e Fisioterapia.

As atividades aqui relatadas foram realizadas semanalmente durante o ano letivo de 2015, nos meses de julho a novembro, junto a 04 escolas da rede pública da cidade. Cada atividade teve duração de cerca de 1 h e 30 minutos, sendo que cada turma de estudantes era acompanhada dos seus professores, que também participaram das ações. Ao total participaram das ações 113 alunos, sendo $51,32 \%$ meninas e $48,67 \%$ meninos, com idade média de 11 anos, e, 5 professores, pois em uma das escolas as ações foram desenvolvidas junto a duas turmas do mesmo ano.

Para abordarmos o tema relacionado aos neuromitos, lançamos mão de uma abordagem lúdica, de acordo com a idade média dos alunos, que consistiu em uma breve explanação teórica seguida de atividades práticas que envolvessem toda a turma em torno do tema trabalhado. Os neuromitos trabalhados, bem como o objetivo e metodologia empregada estão descritos resumidamente no quadro 1 (para mais informações sobre as atividades, materiais e procedimentos, ver FILIPIN, VARGAS e MELLO-CARPES, 2016: POPNEURO: guia prático de atividades para a popularização e divulgação da neurociência).

Quadro 1 - Tema, objetivo e metodologia empregada em cada uma das atividades teóricas e práticas propostas para trabalhar os neuromitos junto à comunidade escolar.

\begin{tabular}{|c|c|c|c|}
\hline $\mathrm{N}^{\circ}$ & Tema abordado & Objetivo & Metodologia empregada na ação \\
\hline 01 & $\begin{array}{l}\text { Usamos apenas } 10 \% \\
\text { da capacidade do } \\
\text { nosso cérebro. }\end{array}$ & $\begin{array}{l}\text { Explicar aos alunos o conceito } \\
\text { de neuromitos e mostrar que, } \\
\text { ao contrário do que eles escutam } \\
\text { na televisão, filmes e outros } \\
\text { meios de comunicação, usamos } \\
100 \% \text { da capacidade do nosso } \\
\text { cérebro o tempo todo. }\end{array}$ & $\begin{array}{l}\text { Foi realizada uma breve explanação com o auxílio } \\
\text { de um notebook e um projetor do tipo datashow } \\
\text { abordando a temática. Após, foi proposto aos } \\
\text { alunos exercitarem seus cérebros com algumas } \\
\text { atividades como: cálculo matemático realizado } \\
\text { mentalmente; labirinto do cérebro (figura 1A). } \\
\text { As atividades desafiadoras requeriam ampla atenção } \\
\text { e função cognitiva, de forma que discutimos com os } \\
\text { alunos se eles realmente acreditavam que nesses } \\
\text { casos estavam usando apenas } 10 \% \text { do seu cérebro. }\end{array}$ \\
\hline 02 & $\begin{array}{l}\text { Teoria localizacionista } \\
\text { das funções cerebrais. }\end{array}$ & $\begin{array}{l}\text { Apresentar aos alunos o conceito } \\
\text { dessa teoria, que se refere à ideia } \\
\text { de que cada parte do nosso cérebro } \\
\text { é a responsável exclusiva de uma } \\
\text { determina função, e mostrar as } \\
\text { áreas do cérebro que são ativas } \\
\text { durante nossas ações cotidianas, } \\
\text { relacionando essa temática com o } \\
\text { tema já trabalhado na ação } 01 .\end{array}$ & $\begin{array}{l}\text { Após uma explicação teórica, foi discutida com os } \\
\text { estudantes a relação entre as diferentes partes e } \\
\text { funções cerebrais, utilizando o "cérebro ativado", } \\
\text { um material pedagógico construído a partir de uma } \\
\text { lâmina isopor com o cérebro desenhado, na qual } \\
\text { foram inseridas luzes "pisca-pisca" (Figura 1B). } \\
\text { A ideia do material é que, diante do comando } \\
\text { para a realização de uma determinada função, a parte } \\
\text { correspondente do cérebro seja ativada, o que é } \\
\text { representado pelo acender das luzes. Diante do } \\
\text { comando "movimente sua perna", por exemplo, } \\
\text { todas as partes do cérebro são ativadas (todo o } \\
\text { cérebro é iluminado), já que, mesmo que haja uma } \\
\text { região motora responsável pelo comando do movimento } \\
\text { da perna, também precisamos de informações } \\
\text { sensoriais, de memória, e outras funções, que são } \\
\text { responsabilidade de outras partes cerebrais, para } \\
\text { realizar um movimento voluntário adequadamente. }\end{array}$ \\
\hline
\end{tabular}


Quadro 1 - Cont.

$\mathrm{N}^{\circ}$ Tema abordado

Objetivo

Metodologia empregada na ação

03 Existem períodos críticos para a aprendizagem. Não existe neurogênese no cérebro maduro.

04 Nosso cérebro possui 100 bilhões de neurônios.

05 Quando dormimos nosso cérebro também dorme.
Trabalhar o conceito de plasticidade cerebral, aprendizagem e memória e neurogênese (nascimento de novos neurônios).
Apresentar a constituição do cérebro humano e como surgiu o neuromito de que temos 100 bilhões de neurônios no nosso cérebro e como ele foi elucidado, introduzindo princípios do papel do cientista.
Discutir a função cerebral durante o período de sono, e conceitos relacionados.
Após a breve apresentação de conceitos relevantes, foi proposta uma discussão sobre a aprendizagem, quando e como ela pode ocorrer, bem como sua relação com o desenvolvimento de novos neurônios no hipocampo, uma região do cérebro intrinsecamente relacionada com a aprendizagem. Um jogo de dominó adaptado com uma tabuada foi utilizado como exemplo na nossa capacidade de aprendizagem (Figura 1C).

Após uma breve aula teórica sobre a organização geral do nosso cérebro, incluindo a desmistificação do neuromito de que temos 100 bilhões de neurônios no cérebro, por meio do relato da pesquisa da professora Suzana Herculado em parceria do professor Roberto Lent (HERCULANOHOUZEL e LENT; 2005), cientistas brasileiros que desvendaram o número de neurônios do nosso cérebro (86 bilhões), foi proposto aos alunos que completassem um cérebro com neurônios de papel (Figura 1D), e após fizessem a contagem dos neurônios em sua totalidade. A ideia dessa dinâmica foi demonstrar que o "erro" perpetuado por esse neuromito baseou-se na ideia de que os neurônios se distribuíam de forma igual pela área cerebral. $\mathrm{Na}$ dinâmica os estudantes puderam perceber que o $\mathrm{n}^{\circ}$ de neurônios não era igual nos diferentes lobos cerebrais, assim, a proposta dos cientistas brasileiros resultou em um $\mathrm{n}^{\mathrm{o}}$ mais exato de neurônios porque considerou todo o cérebro humano na sua contagem, e não apenas uma amostra.

Foi realizada uma breve discussão teórica acerca da importância do sono e das funções que o cérebro desempenha durante esse período, tais como consolidação da memória, regulação da produção de hormônio do crescimento, etc. Após, foi proposta a atividade "Tô ligado". Para esta atividade utilizamos uma ilustração do corpo humano em uma folha de isopor na qual era possível identificar os principais, órgãos corporais (Figura 1E). Com tal material discutimos que, mesmo durante o sono, esses órgãos precisam manter seu funcionamento, portanto, nosso encéfalo precisa manter-se funcionando.

Em uma explanação teórica adaptada à idade dos estudantes foram discutidas as bases neurobiológicas da linguagem e os possíveis efeitos da aprendizagem de um idioma no cérebro humano. Após, foi proposta a atividade "racha cuca", na qual pedimos ao participante que lesse as palavras que eram mostradas (as palavras correspondiam a nomes de cores, por exemplo, laranja), após, pedimos para que nos relatassem a cor com que as palavras estavam escritas (e não a palavra em si). Nesta atividade é comum nosso cérebro confundir-se, visto que ocorre um conflito entre a informação visual da cor e da palavra (a palavra laranja, por exemplo, poderia estar escrita na cor azul; figura $1 \mathrm{~F}$ ). 


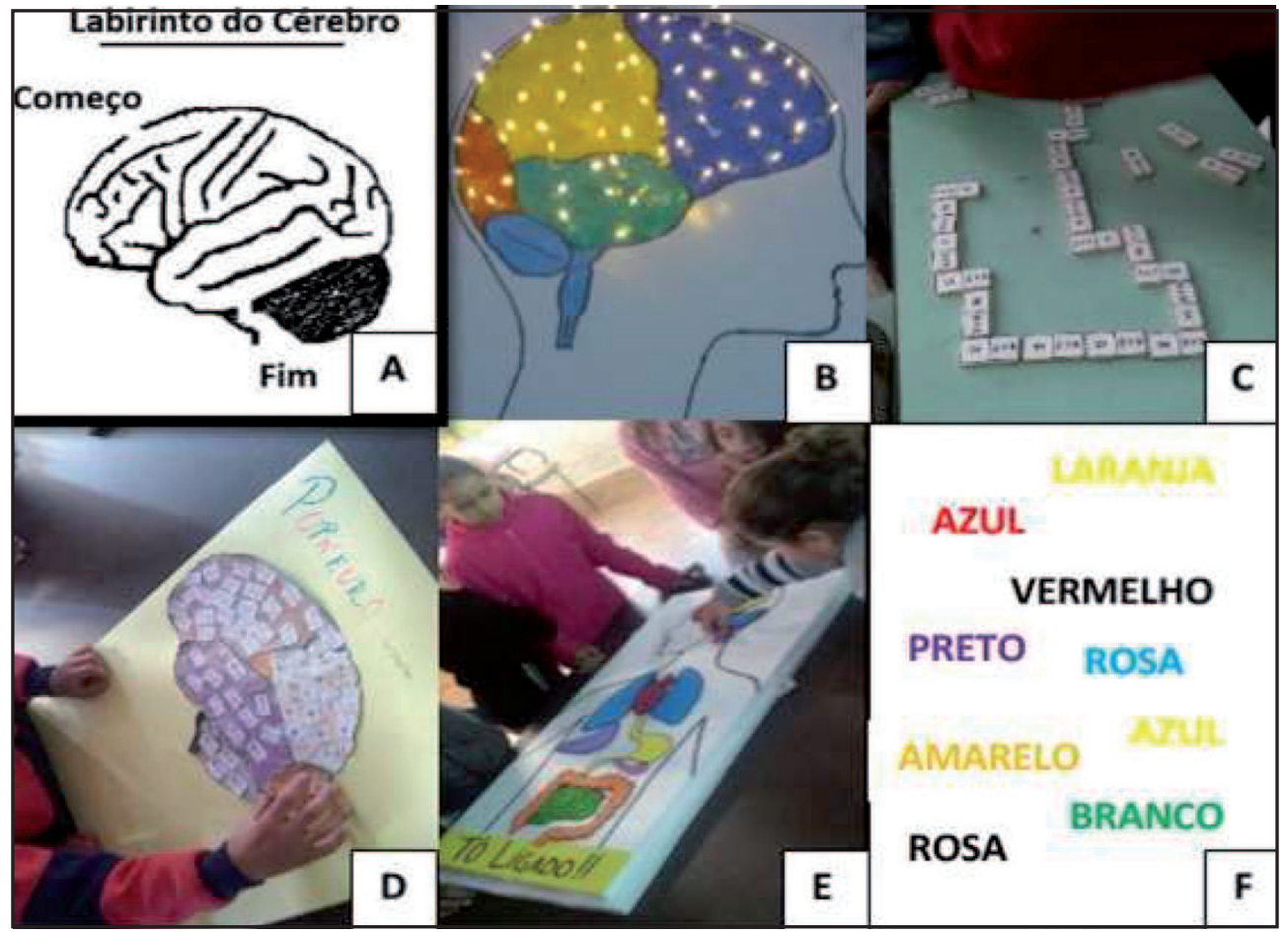

Figura 1 - Imagens ilustrativas das atividades práticas realizadas durante as intervenções com os alunos. Fonte: Material elaborado pelos autores (2016).

Para avaliar o impacto das ações propostas, convidamos os alunos participantes para responder a um questionário estruturado sobre o assunto abordado antes e após cada ação. Após as ações, também convidamos os professores das turmas participantes para que avaliassem as atividades. $\mathrm{O}$ quadro 2 apresenta as principais perguntas utilizadas nos questionários dos alunos e professores. A maioria das perguntas incluídas nos dois questionários propostos aos estudantes (pré e pós) eram as mesmas, de forma que os resultados poderiam ser comparados. Adicionalmente, no questionário aplicado após as ações, pedimos que os participantes avaliassem as ações realizadas, atribuindo uma nota de 0 a 10, sendo 0 a menor nota e 10 a maior.

Após um mês das atividades descritas, foi solicitado aos estudantes participantes que respondessem a um questionário contendo as mesmas questões da tabela 2 (avaliação tardia), para assim, ter uma melhor avaliação do impacto das atividades realizadas.

Os resultados foram tabulados e são apresentados na forma de percentuais para questões cujas opções de resposta eram "SIM" ou "NÃO", ou média \pm desvio-padrão, no caso da nota atribuída às ações realizadas.

\section{Resultados}

Nossos resultados demonstram que as ações propostas foram exitosas, auxiliando na elucidação de neuromitos e na divulgação científica, uma vez que houve um aumento dos conhecimentos dos alunos a respeito dos temas abordados (figura 2).

Ao final das intervenções, considerando uma escala de 0 a 10, os alunos atribuíram uma nota média de 9,6 para as atividades trabalhadas durante as intervenções.

Os professores também demonstraram interesse nas temáticas. Na ação $01,80 \%$ dos professores afirmaram não ter conhecimento de outros neuromitos previamente às nossas intervenções. Na ação 02 , todos os professores afirmaram que sabiam que as diferentes áreas do cérebro são interligadas. $\mathrm{Na}$ ação $03,100 \%$ dos professores consideraram a plasticidade neural importante para o contexto escolar. $\mathrm{Na}$ ação 04 , todos afirmaram saber que possuímos aproximadamente 86 bilhões de neurônios. Na ação 05, todos os professores afirmaram que, a partir da ação desenvolvida, buscariam métodos para incentivar os alunos a terem uma maior qualidade de sono, já que isso tem implicação importante para a aprendizagem escolar. E, na ação $06,80 \%$ dos professores disseram que sabiam que aprender outro idioma melhora as funções cerebrais. 
Quadro 2 - Principais perguntas utilizadas nos questionários para avaliação das ações pelos alunos e professores participantes.

\begin{tabular}{|c|c|c|}
\hline Ação & $\begin{array}{c}\text { Questionários aplicados aos alunos } \\
\text { (pós-ação) }\end{array}$ & $\begin{array}{c}\text { Questionários aplicados aos professores } \\
\text { (pré e pós-ação) }\end{array}$ \\
\hline 01 & $\begin{array}{c}\text { Você acha que usamos } 100 \% \text { da capacidade } \\
\text { do nosso cérebro o tempo todo? } \\
\begin{array}{cc}\text { ( ) SIM } & \text { ( ) NÃO }\end{array}\end{array}$ & $\begin{array}{l}\text { Você tem conhecimento de outros neuromitos, } \\
\text { além desse que discutimos hoje? } \\
\begin{array}{ll}\text { ( ) SIM } & \text { ( ) NÃO }\end{array}\end{array}$ \\
\hline 02 & 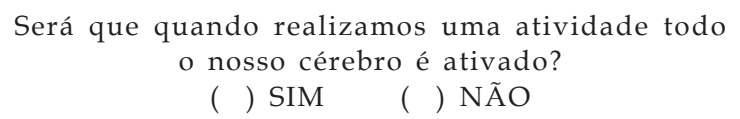 & $\begin{array}{l}\text { Você já tinha conhecimento que todas as } \\
\text { áreas do nosso cérebro estão interligadas? } \\
\begin{array}{ll}\text { ( ) SIM } & \text { ( ) NÃO }\end{array}\end{array}$ \\
\hline 03 & $\begin{array}{l}\text { Você acha que o nosso cérebro aprende } \\
\text { que ela apenas até um determinado período } \\
\text { da nossa vida? } \\
\begin{array}{cc}\text { ( ) SIM } & \text { ( ) NÃO }\end{array}\end{array}$ & $\begin{array}{c}\text { Em relação à plasticidade neural, você acha que } \\
\text { é importante para o aprendizado em } \\
\text { sala de aula? } \\
\begin{array}{cc}\text { ( ) SIM } & (\text { ) NÃO }\end{array}\end{array}$ \\
\hline 04 & $\begin{array}{l}\text { Você sabe quantos neurônios possuímos em } \\
\text { nosso cérebro? } \\
\begin{array}{ll}\text { ( ) SIM } & (\text { ) NÃO }\end{array}\end{array}$ & $\begin{array}{c}\text { Você já sabia que nosso cérebro possui } \\
86 \text { bilhões de neurônios? } \\
\begin{array}{c}\text { ( ) SIM } \quad \text { ( ) NÃO }\end{array}\end{array}$ \\
\hline 05 & $\begin{array}{l}\text { Nosso cérebro está ativo } 24 \mathrm{~h} \text { por dia? } \\
\begin{array}{ll}\text { ( ) SIM } & \text { ( ) NÃO }\end{array}\end{array}$ & $\begin{array}{c}\text { A partir desta aula, você buscaria métodos para } \\
\text { incentivar os alunos a terem uma } \\
\text { melhor qualidade de sono? }\end{array}$ \\
\hline 06 & $\begin{array}{l}\text { Você acha que seu avô pode aprender } \\
\text { outro idioma? } \\
\begin{array}{ll}\text { ( ) SIM } \quad \text { ( ) NÃO }\end{array}\end{array}$ & $\begin{array}{c}\text { ( ) SIM ( ) NÃO } \\
\text { Você sabia que aprender outro idioma } \\
\text { melhora as funções cerebrais? } \\
\begin{array}{c}\text { ( )SIM } \quad \text { ( ) NÃO }\end{array}\end{array}$ \\
\hline
\end{tabular}

Fonte: Material elaborado pelos autores (2016).

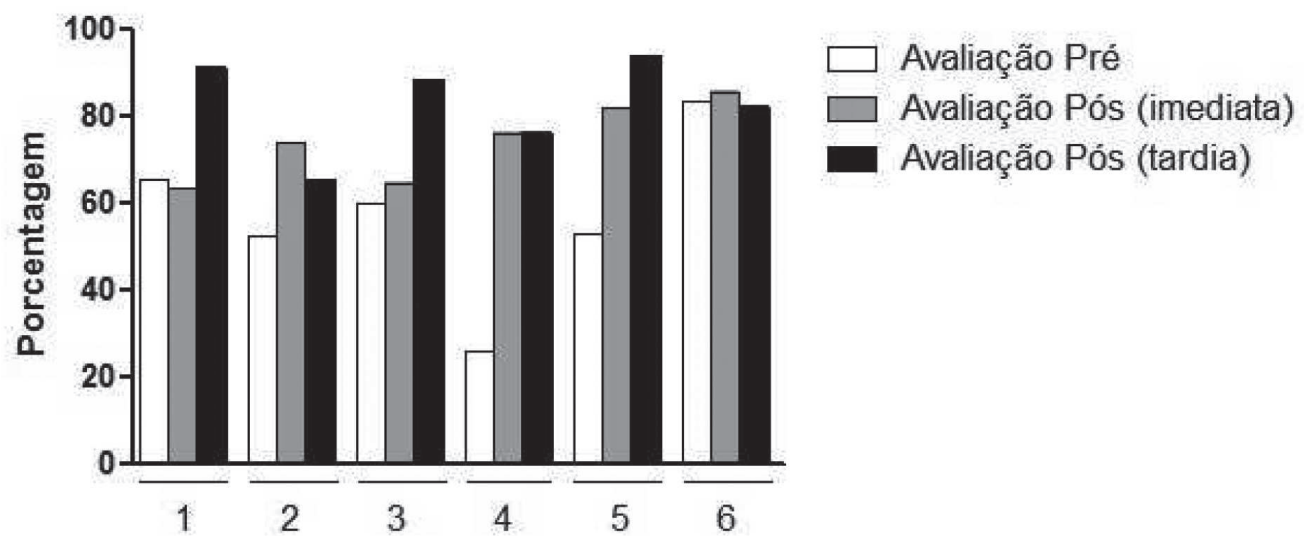

Figura 2 - Percentual de respostas corretas dadas pelos estudantes às perguntas 1 à 6, antes (avaliação pré), imediatamente após (avaliação pós imediata) e um mês após as ações realizadas (avaliação pós tardia). Amostra de 94 estudantes.

Fonte: material elaborado pelos autores (2016).

\section{Discussão}

As ações desenvolvidas resultaram em interesse dos estudantes e professores pelos temas abordados. Acreditamos que esse interesse se deu pela forma como os neuromitos foram trabalhados nas escolas, já que foram propostas atividades práticas e lúdicas para um melhor envolvimento e entendimento. Como afirma Vargas et al. (2014), o aprendizado ocorrerá de maneira mais efetiva quando são utilizados recursos que envolvam o lúdico e o atrativo.

A crença em alguns neuromitos, verificada por meio da avaliação inicial, demonstra a importância de se abordar dentro da sala de aula conceitos e temáticas relacionadas à neurociência e à ciência básica que não estão presentes no plano de ensino das aulas, mas que indiretamente estão presente no cotidiano dos alunos (FILIPIN et al, 2015). Sem ter essas informações no ensino formal os alunos acabam procurando-as em espaços mais informais e com pouco compromisso com a ciência, como a 
internet, o que pode gerar má interpretação e contribuir para propagação desses conceitos equivocados. Pasquinelli (2012) ressalta que os neuromitos existem por três fatores: pela desinformação, pela distorção dos fatos científicos, ou seja, má interpretação, e pela ansiedade da população em saber as notícias sobre o cérebro que faz com que ela acabe crendo em tudo que lê, sem buscar, necessariamente, uma fonte de veracidade.

Dessa forma, é importante que esses conceitos sejam trazidos para o dia a dia de uma forma adaptada, e não simplificada, assim, conceitos importantes e que tem repercussão no dia a dia das pessoas poderão ser esclarecidos de forma responsável. Por exemplo, é importante que as pessoas saibam que durante o sono a nossa memória é consolidada, há reparação dos tecidos do corpo, hormônios são liberados (LENT, 2008), assim, elas terão um maior cuidado com a qualidade do seu sono e entenderão que o nosso cérebro está ativo 24 hs por dia. Nossos resultados demonstram que essa temática apresentou a segunda maior em diferença entre o percentual de respostas corretas na avaliação pré em relação à avaliação pós tardia. Saber que utilizamos $100 \%$ da nossa capacidade cerebral, e que o córtex cerebral possui cerca de 86 bilhões de neurônios organizados em complexos circuitos, que são responsáveis pelas funções cognitivas, tais como linguagem, memória, planejamento, emoções, não havendo assim, qualquer parte do cérebro inerte (CONSENZA; GUERRA, 2011), também é importante para entendermos como esse órgão funciona e não acreditarmos em qualquer informação e/ou produto que nos é apresentado, como as estratégias milagrosas, medicamentosas ou não, que são ofertadas por aí prometendo fazer com que o nosso cérebro funcione a $100 \%$ de sua capacidade.

Ainda, com a má interpretação textual surgiu o neuromito de que aprendemos apenas em um determinado período da nossa vida, chamado de período crítico para a aprendizagem. Porém, graças aos avanços científicos, sabemos que, embora nosso cérebro esteja mais sensível a aprender nos primeiros anos de vida, uma vez que tudo é novo para nós nessa fase, o nosso cérebro é um órgão plástico, ou seja, se reorganiza a cada novo aprendizado durante toda a nossa vida. Como afirma Roballo et al. (2016), a plasticidade cerebral é a capacidade do cérebro de formar e reformar as ligações entre os neurônios, sendo a plasticidade umas das responsáveis pela aprendizagem, a qual não cessa durante toda a vida, o que auxilia para que se reforce a ideia de que idosos são sim capazes de obterem aprendizado, como aprender um novo idioma, utilizar o computador, celular, etc.

Quando falamos em neuromitos, é importante considerar que os professores possuem um papel fundamental nesse contexto, pois podem contribuir para evitar a perpetuação desses conceitos equivocados, desde que tenham conhecimentos para tal. Um dado preocupante foi o resultado da primeira ação, na qual $80 \%$ dos professores afirmaram que não sabiam da existência de outros neuromitos, além do que foi abordado na referida ação. Tal dado demonstra a necessidade de incluirmos conceitos de neurociência na formação inicial e continuada dos professores da Educação Básica.

Filipin et al. (2015), afirma que os conhecimentos sobre neurociência advindos de cursos de formação continuada para professores podem ajudar na metodologia de suas aulas, pois assim, conteúdos de neuroanatomia, neurofisiologia, neurobiologia, serão considerados na elaboração de suas metodologias de ensino, contribuindo significativamente para o processo ensino-aprendizagem de seus alunos. Nesse sentido, o programa POPNEURO, além das intervenções realizadas com a comunidade escolar, desde 2013 realiza anualmente o curso de Neurociência Aplicada à Educação para professores da rede pública de Uruguaiana e região. O curso aborda temas que tangem a neurociência, com atividades teóricas e práticas que podem ser desenvolvidas em quaisquer espaços físicos.

É importante destacar que o programa POPNEURO como um todo, assim como as ações aqui relatadas, propõem uma abordagem interdisciplinar, que vai desde a constituição de sua equipe, até o conteúdo das ações propriamente dito. Tal interdisciplinaridade entre o campo da Saúde/Ciências Biológicas e da Educação é, sem dúvida, relevante e deve ser uma das características destacadas no programa. Essas ciências, embora tratadas como tão diferentes, estão intimamente relacionadas. Se considerarmos que o objetivo principal da educação é a aprendizagem, é fundamental questionar-se como, em termos neurobiológicos, o cérebro aprende, bem como quais são os efeitos de diferentes intervenções ou situações que contribuem ou prejudicam a aprendizagem. Por outro lado, a neurociência precisa considerar as experiências e saberes que os profissionais da educação, que estão em contato direto com os sujeitos aprendentes, trazem, para então nortear suas pesquisas. Diversos são os caminhos que relacionam, em uma via de mão dupla, essas ciências, e esse é um dos aspectos que o programa prima: a valorização dos saberes de cada uma, considerando que elas podem se somar e se complementar. Na própria equipe executora do programa sempre procuramos ter um grupo 
interdisciplinar. Dentre os docentes pesquisadores participantes, por exemplo, um é da área da Saúde, um das Ciências Biológicas e um da Educação, e os alunos são oriundos de diversos cursos, incluindo licenciaturas e bacharelados.

Dessa forma, ações como as aqui propostas são importantes, pois, sabendo que ainda existem muitos neuromitos em sala de aula, é importante desmistificar essas informações, e essas ações extensionistas demonstram ser uma boa estratégia para a divulgação de informações científicas, pois, além do compartilhamento das informações, elas têm o poder de integrar a sociedade e Universidade (MARTINS; MELLO-CARPES, 2014). Nesse viés, a popularização da neurociência carece de dedicação e cuidado para que haja seu pleno entendimento pela comunidade não acadêmica. Para isso, o uso de uma linguagem adaptada, e não apenas simplificada, é de fundamental importância (BROCKINGTON; MESQUITA, 2016) para que as ações, tão bem-intencionadas, não acabem tendo o efeito inverso, e transmitindo mais mitos relacionados ao funcionamento do cérebro. Dessa forma, procuramos trabalhar temáticas complexas da neurociência de uma forma fácil de ser compreendida, utilizando de diferentes propostas/dinâmicas de ensino, fazendo com que a ciência se aproximasse da comunidade, de forma que ela pudesse se apoderar de assuntos até então distantes, proporcionando, dessa forma, interesse pelo saber científico.

Destaca-se assim, a efetividades das ações, demonstrada também pela avaliação tardia, na qual percebemos que os entendimentos permaneciam mesmo um mês após as ações (efeito a longo prazo), o que reforça que as atividades foram bem-aceitas pelos alunos, pois percebeu-se plena atenção durante a teoria e principalmente durante as práticas, que tiveram grande adesão.

É preciso considerar, ainda, o impacto que a participação nesse programa de extensão teve/tem junto aos alunos de graduação e pós-graduação membros da equipe. O POPNEURO completa, em 2017, 4 anos de existência, período durante o qual cerca de 40 estudantes universitários tiveram a oportunidade de participar do programa. A maioria dos estudantes que ingressa no programa é estudante de graduação, e acaba permanecendo nele até o final do seu curso, sendo a conclusão do curso o principal motivo para a saída da equipe. A motivação em participar do programa certamente está relacionada com o retorno que os alunos veem a cada ação. A agenda de atividades é intensa: uma reunião científica semanal de toda equipe para leitura e discussão de artigos científicos, uma reunião de avaliação das ações já realizadas e programação das ações a serem realizadas, além de encontros das equipes de trabalho (subgrupos) para construção de propostas didáticas, materiais de apoio, etc. e, é claro, da ação propriamente dita, realizada 1 vez por semana em cada escola (cada subgrupo de trabalho é responsável por uma escola) (FILIPIN et al., 2015). Mesmo com a grande demanda de trabalho, percebe-se que os graduandos desenvolvem um grande amor pelo projeto, pois percebem que os professores, e, principalmente, os estudantes da Educação Básica valorizam as ações, aproveitando-as ao máximo. Essa valorização também se reflete em valorização do trabalho dos membros da equipe, o que os motiva a qualificar-se cada vez mais para as ações. Dessa forma, o programa incentiva a leitura científica, o estudo de temáticas relevantes para os estudantes dos diferentes cursos de graduação, e promove o contato com a sociedade, mais especificamente com a escola, proporcionando ao universitário uma formação extensionista, com ênfase em habilidades de divulgação e comunicação científica. Dessa forma, os benefícios do programa são mútuos, atingindo não somente professores e alunos da Educação Básica, mas também os membros da equipe executora.

\section{Conclusões}

As ações realizadas para discutir temas atuais relacionados com a neurociência, educação e elucidação dos neuromitos foram efetivas, visto que proporcionaram melhor compreensão do cérebro e suas funções tanto por alunos quanto por professores da Educação Básica. Assim, este programa atingiu seus objetivos, pois as intervenções propostas permitiram compreender conceitos que inicialmente pareciam complexos demais, de forma simples, lúdica e, principalmente, prática, contribuindo assim, para que esses temas sejam trabalhados com mais frequência, evitando a perpetuação de neuromitos.

\section{Fontes de financiamento}

Os recursos para execução das ações descritas foram obtidos por meio da Pró-reitoria de Extensão da Universidade Federal do Pampa, por meio de editais de fomento à extensão (PROEXT/Unipampa), 
do Ministério da Educação, pelo Edital PROEXT/MEC 2015, e da Coordenação de Aperfeiçoamento de Pessoal do Ensino Superior (CAPES), pelo Edital Novos Talentos/CAPES e, em cooperação com o British Council (Newton Fund), do Edital de Cooperação Internacional STEM CAPES/BC.

\section{Agradecimentos}

Os autores agradecem as agências de fomento acima mencionadas, por garantirem os recursos necessários para execução das ações propostas. Da mesma forma agradecem as escolas públicas parceiras deste projeto, que acreditaram na importância da temática e abriram suas portas para nossa equipe. Por fim, agradecem aos demais alunos de graduação e pós-graduação que atuaram no programa como bolsistas e voluntários, garantindo a execução das ações propostas pela equipe.

\section{Referências}

BUENO, O. F. A.; EKUNI, R.; ZEGGIO, L. Caçadores de neurônios: o que você sabe sobre seu cérebro é verdade? . São Paulo: Memnon, 2015.

BROCKINGTON, G.; MESQUITA, L. As consequências da má divulgação científica. Revista da Biologia 15(1):9-14. 2016. Disponível em: < http:www.ib.usp.br/revista/node/207>. Acesso em: 20 jan 2017.

CONSENZA, R. M.; GUERRA, L. B. Neurociência e educação: como o nosso cérebro aprende. Porto Alegre. Artmed. 2011

DEKKER, S.; LEE, N. C.; HOWARD-JONES, P.; JOLLES, J. Neuromyths in education: Prevalence and predictors of misconceptions among teachers. Frontiers in Psychology. 2012.

FILIPIN, G.; PERRONI, B. M.; MARTINS, A. S.; MELLO-CARPES, P. B. Despertando a curiosidade de escolares sobre o cérebro por meio de visitas semanais de estudantes de neurociência à escola. Revista de Ensino de Bioquímica. v.13, n.3. p. 100-112. 2015.

FILIPIN, G. E.; VARGAS, L. S.; MELLO-CARPES, P. B. (Orgs). Popneuro: guia prático de atividades para a popularização e divulgação da neurociência. 176 p. 1 ed.São Paulo: Livrobits, 2016.

FILIPIN, G. E.; CASAROTTO, F. D.; MARONEZE, B. M.; MELLO-CARPES, P. B. POPNEURO: Relato de um Programa de Extensão que busca divulgar e popularizar a neurociência junto a escolares. Revista Brasileira de Extensão Universitária, v. 6, n. 2, p. 87-95, 2015. Disponível em: <https:// periodicos.uffs.edu.br/index.php/RBEU/article/view/3066/pdf >. Acesso em: 20 jan. 2017.

HERCULANO-HOUZEL, S., LENT, R. Isotropic Fractionator: A Simple, Rapid Method for the Quantification of Total Cell and Neuron Numbers inicio the Brain. The Jornaul Of Neuroscience. v. 25, n. 10, p. 2518-2521. 2005

LENT, R. Neurociência da mente e do Comportamento; Editora: Guanabara Koogan; pg. 372. 2008

NEWTON, P.M., (2015). The Learning Styles Myth is Thriving in Higher Education. Front. Psychol. 6:1908.

Organisation for Economic Cooperation and Development. Understanding the Brain: Towards a New Learning Science, OECD, Chapter 4.6 pp. 69-77. 2002.

Organisation for Economic Cooperation and Development. Understanding the Brain: Towards a New Learning Science. Paris: OECD. 2007.

PASQUINELLI, E. Neuromyths: Why do they exist and persist? Mind, Brain, and Education, 6, 89-96. 2012.

RATO, J. R.; ABREU, A. M.; CASTRO-CALDAS, A. Neuromyths in education: what is fact and what is fiction for Portuguese teachers? Educational Research, 2013.

ROBALLO, R.; SILVA, V. F.; FENNER, B. P.; TIECHER, C. R.; CRESPO. B. T. T. Plasticidade cerebral. In: FILIPIN, G. E.; VARGAS, L. S.; MELLO-CARPES, P. B. (Orgs). Popneuro: guia prático de atividades para a popularização e divulgação da neurociência. 176 p. 1ed. São Paulo: Livrobits, 2016. 
VARGAS, L. da S.; MENEZES J; ALVES N.; SOSA, P.; MELLO-CARPES, P. B. Conhecendo o Sistema Nervoso: Ações de Divulgação e Popularização da Neurociência junto a Estudantes da Rede Pública de Educação Básica. Ciência \& Cognição, 19, p. 233-41. 2014.

Recebido para publicação em 5/1/2017 e aprovado em 23/3/2017. 